\title{
High speed track on the Western Region of British Railways
}

\author{
R. J. COLLINS. J. BLACK \\ \& J. E. TYRER
}

\section{Messrs Collins, Black and Tyrer}

The planning of maintenance work, particularly mechanized maintenance, using ontrack machines has been based mainly on the monthly 'black box' records (cf. § 66) depicting aspects of the vehicle ride. An analysis of the mechanized maintenance carried out during the first year has shown that, as an overall average, the frequency of tamping/lining has been about twice per year. There has, however, been a considerable variation over different sections of the route, ranging from 1.3 times per year to 2.8 times per year.

71. Records from the new British Railways high speed track recording car and its predecessor, the Research Department's TRIM vehicle, have been used to detect changes in track geometry, both in the top and in the alignment, which are measured in terms of standard deviations from the ideal profiles. These showed that the overall quality did not vary much during the year, although there was a slight improvement in alignment. The latter tended to be better than the top, confirming the initial impression that greater emphasis is needed on the maintenance of the vertical profile. This applies particularly to such aspects as welds and washy places where the ballast condition has deteriorated or failed.

72. Local washy places have had to be dealt with quickly to avoid the usual spreading into a full ballast cleaning item. The most effective way of dealing with them has been to dig out the cribs and beds using lightweight hammers with spade attachments and then to use the same basic tools with compactor head attachments to consolidate the new ballast. This has been successfully carried out without a temporary restriction of speed even on the high speed route. The fact that washy places do still appear, usually where the full $300 \mathrm{~mm}$ depth of ballast had not been achieved, has emphasized the need for the large programme of ballasting described in the Paper.

73. The first year has amply demonstrated that in order to retain the high standards of track geometry required for satisfactory high speed running, preventive maintenance of the track is essential in every aspect. The unplanned imposition of temporary restrictions of speed would quickly destroy the high speed service which depends, not only on the high speed running, but on a short turn-round time at the terminals.

Mr P. Rees, British Rail, Western Region

According to the Paper, reballasting, including blanketing, was carried out on 108 miles of track prior to the introduction of the high speed trains, and that was only $43 \%$ of the total track length between Paddington and Bristol Parkway on the one hand and Box

Paper published: Proc. Instn Civ. Engrs, Part 1, 1978, 64, May, 207-225. 
Tunnel on the other. The remainder was found from trial holing to be in satisfactory condition, and experience has proved that, by and large, that was right. On the London Division, until about 1972, the ballast used was from Frome quarry, having a wet attrition value of $7 \cdot 7$, and there is still a lot of that ballast in use. Reballasting is not a once-only job; it will continue, perhaps at a rather increased rate, until the Frome ballast has been replaced.

75. It is likely that the Frome ballast will not last more than ten years and perhaps even less in places. It is hoped that the ballast now being used, which comes from South Wales and has a wet attrition value of only 4 , will last noticeably longer, hopefully 15 years. If it does not, some much faster and heavier duty ballast cleaning machines may have to be devised to cope with the necessary workload.

76. The long blockage of the Badminton line was an essential means of getting the work done in time; it enabled the work to continue round the clock, unaffected by normal traffic. It also had its effect on the manpower and organization of the Division. It involved tremendous planning-very good planning, as the events proved. But undertaking a major project of this kind does drain resources from other parts of the Division. In the case of the Bristol Division, priority had to be given to the Badminton line. At the end of the blockade it was necessary to go back and give greater attention to the diversionary route via Bath, where there was quite a mileage of jointed track west of Chippenham. I was personally glad when the five-month blockade was over and it was possible to get back to something more in the way of normal maintenance on that line. If there is another blockade of those proportions, perhaps it will be a little shorter than five months. I would think we could stand two or three months.

77. In the layout improvements, British Rail has insisted that the switch and crossing work is on the straight wherever possible. There have been one or two cases where that was not achievable, and we have accepted that the work can be laid in a flat curve (200 chains radius minimum without cant). I do not think we have suffered a great deal as a result of that, but it is much easier to maintain correct alignment on the straight.

78. Regarding the elimination of fixed diamonds on the London Division, I would extend that to the whole route. There are only seven fixed diamonds left in the main line between Paddington and Bristol Parkway; five of those are in the immediate Reading area, where perhaps we shall eventually have a major layout alteration and get rid of them. For the time being they have to have extra maintenance. The one fyat cannot be removed in the foreseeable future is at Wootton Bassett; that will remfin as a double junction, but the elbows will be movable.

79. The crossings were almost invariably cast manganese crossings, which are good in many ways, but there do seem to be difficulties in making a casting without any defects. Several have had to be changed or welded. The alternative is the swing nose crossing; there are only two of these on the Western Region, both in the track at Dolphin Junction near Slough. These are proving very successful. They may be used more in the future in order to get the smooth run that is necessary on the high speed tracksunless some new technique enables the makers to provide much better cast manganese crossings.

Mr S. R. D. Power, Chief Mechanical and Electrical Engineer, British Railways Western Region

The policy decision to operate the high speed trains on the existing network, albeit with considerable improvements to the permanent way, has meant that the engineers involved with the design of the train have had to work within limits set by the Civil Engineer and the Signal and Telecommunications Engineer.

81. In order to keep within the vertical and lateral forces specified by the Civil Engineer, it has been necessary to dispense with the more conventional axle-suspended traction motor and adopt a system incorporating bogie-mounted motors. This greatly reduces the unsprung weight on the axle but necessitates the provision of a 
complex flexible drive arrangement between the motor and the axle in order to allow relative movement to take place between the motor and the axle which it drives. As might be expected, there have been teething problems with this flexible drive, but modifications are now being implemented which, it is felt with confidence, will overcome the current difficulties.

82. To permit the train to operate within the present signalling system, it has been designed to stop from $125 \mathrm{mile} / \mathrm{h}$ within the same distance that it takes a conventional train to stop from $100 \mathrm{mile} / \mathrm{h}$. There is no difficulty in applying greater brake forces; the problem arises should the limit of adhesion between wheel and rail be exceeded, permitting the wheel to slide on the rail and cause a flat on the running surface of the wheel. Apart from the damage to the track work caused by the wheel flats, the defect on the vehicle is costly to rectify both in terms of time out of service and money. To prevent this happening an electronic device, fitted to each wheel set, measures the rate of deceleration, and before a wheel slide can take place the device, acting in anticipation, off-loads the air pressure from the appropriate brake cylinder, restoring it a few seconds later when the tendency to slide has been averted.

83. With reference to the ride quality of the Mark 3 passenger coach; as far as the wheel-rail relationship for power cars and coaches is concerned, the very low wheel wear rate indicates a highly satisfactory solution from the point of view of both the Civil Engineer and the Mechanical Engineer. In my opinion, generally speaking, the coaches ride well. It must be realized that the ride-meter tests were taken in the worst possible position, namely in the end corner of the coach adjacent to the power car. The Design Engineer is aware that the present buckeye-gangway coupling arrangement transmits and superimposes the power car movement on to that of the adjacent coach. The problem is currently under investigation to determine what remedial action is necessary.

84. I regularly travel on the footplate of the high speed train and all the drivers I have spoken to have expressed every confidence in the quality of the $125 \mathrm{mile} / \mathrm{h}$ track. I would like to take the opportunity to thank the Civil Engineer of the Western Region and all his staff for providing a first class permanent way for the new trains.

\section{Mr G. H. Cope, British Railways Board}

I would refer to the question raised by $\mathrm{Mr}$ Rees about the problems we have had with cast manganese crossings. In conjunction with the Railway Technical Centre at Derby, we are investigating a number of ways of forming solid common and obtuse crossings, as alternatives to the use of cast austenitic manganese steel. Some of these offer considerable possibilities. Because they will use much smaller quantities of cast metal, we expect ultimately to achieve higher quality in terms of lack of internal flaws, and the use of steel of appropriate metallurgical quality will ensure that the wearing quality of the crossings will not be diminished.

86. We are continuing to develop swing nose crossings, and we hope for considerable success in that field over the next two or three years.

87. Speaking as a permanent-way engineer, I am very relieved to hear Mr Power's contribution on the unsprung weight in the locomotives and on the quality of wheel slide control that can be achieved. Table 1 shows that although the high speed train has quite a substantially low unsprung mass per wheel compared with any of its predecessors, it has also, at $125 \mathrm{mile} / \mathrm{h}$, a substantially higher $\boldsymbol{P}_{1}$ force than its predecessors. The $\boldsymbol{P}_{1}$ force is that force which is caused by the passage of a laden wheel over a dipped rail joint. Since there are not many rail joints on these high speed lines, one might be forgiven for thinking that very largely the figure is irrelevant-compared with the $\boldsymbol{P}_{2}$ force, which is the force which causes the general deformation of sleepers. As that force has been demonstrated to be considerably lower with the high speed train than it was with some of its predecessors, one might think we were all right. Unfortunately, some of the work carried out recently at Derby on the effect of wheel flats is revealing some disturbing information. 
88. A wheel flat produces very much the same effect on the track as when a vehicle passes over a dipped rail joint. In the early stages of the study on wheel flats, one of the devices resorted to by the researchers at Derby was to grind a depression in the head of the rail, which looked similar in its form to a dipped rail joint, and using that they were able to investigate the forces and stresses in the locality.

89. At one stage in 1977, however, the conclusion was reached that we had to run a train of prepared wheel-flatted vehicles on a test track over load-measuring base plates and over sleepers which were fitted with electrical resistance strain gauges at the vital points. We then discovered that if the wheel flat coincided with the sleeper on which the strain gauges were mounted (on the upper surface of the sleeper), one obtained not only the expected high compressive stress in the top fibres of the sleeper as the wheel went past, but there was also a rebound. Immediately following the substantial compressive stress, there was quite an appreciable level of tensile stress developing.

90. The standard British Rail concrete sleeper is designed to resist bending mainly in a sagging downwards formation. What is happening is that, under the impulse load or the hammer blow of the wheel flat, the sleeper is not only forming a concave shape but, for at least one rebound, it is ringing as if it were a tuning fork, and moving from the concave downwards to the convex upwards form, thereby setting up the tensile forces. Since the level of prestress in the upper fibres of the standard sleeper is fairly low, one begins to wonder whether one will not get cracking of the sleeper under these loads, at sleepers which coincide with wheel flats. This explains the considerable concern about wheel flats, and my own personal satisfaction therefore at Mr Power's assurance that there is wheel slide control on these locomotives.

91. One of our problems is the environmental one of the noise level produced by trains, particularly in built-up areas. We are learning that the disc brakes can have quite a pronounced effect on this. Wheels which are braked with cast iron tread brakes tend to have a great many more irregularities on them than the ones with disc brakes, even though the tread brake will wear away the flat. This shows itself in the general tendency of a disc-braked train to be quieter than a tread-brake vehicle. However, if the train runs over corrugated rail the difference is much more noticeable. People have said that the high speed train actually sounds louder than the conventional one. The truth is that it is the contrast between the exceptional quietness of the high speed train over good track, and its behaviour (almost exactly the same as a normal train's) where the track surface happens to be corrugated.

The Chairman, Mr A. M. Muir Wood, President

I believe that during the last few years there have been great advances in considering the track, including its foundation, and the vehicle as a single dynamic system. Is there anything to be said on this topic in relation to the Paper under discussion?

93. What is the cost of permanent way maintenance, in relation to that prior to the introduction of the high speed train. The standards to which the formation has to be maintained are presumably higher, because for example of sensitivity to the effects of slips, whereas one could otherwise afford to have a bit of a sag for normal traffic.

94. What is the increase in traffic on the route on account of the high speed train being introduced?

\section{Mr M. C. Purbrick, British Railways Board}

The only other railway which runs high speed trains at this sort of intensity of service is the Japanese National Railway on the Shinkansen line. This is a specially built railway dedicated to high speed trains.

96. The cost of constructing this new railway in Japan was of the order of 100 times the amount which was spent on preparing the track for the Western Region services. The cost of track maintenance on the Shinkansen line is at least twice the cost that we are incurring in maintaining the Western Region 125 mile/h services. It is therefore an 
excellent project from the point of view both of the initial capital cost and also of the cost-effectiveness of the maintenance currently carried out.

97. The high speed recording car is a relatively new development and gives for the first time an accurate means of assessing track quality. Until now there has always been personal judgement involved.

98. The standard deviation figures of $1.9 \mathrm{~mm}$ for vertical quality and $1.3 \mathrm{~mm}$ for alignment quality relate to the degree of acceleration that is comfortable for the human body. These particular figures have not yet been accepted as final. This is an important step forward: it is a tool for British Railways to use to make its maintenance in the future even more cost-effective.

\section{Mr E. A. Labrum. British Railways, London Midland Region}

London Midland Region is about to introduce the advanced passenger train on the West Coast main line at $125 \mathrm{mile} / \mathrm{h}$. Problems have already been encountered due to the intensive $100 \mathrm{mile} / \mathrm{h}$ service on that route affecting insulated joints and site welds at places where there is ballast deterioration. What experience have the Western Region engineers obtained of any accelerated deterioration in those two features associated with $125 \mathrm{mile} / \mathrm{h}$ traffic?

100. As a section of the Western Region line was closed for five months, it might well have been expected that some other form of track design, such as slipform concrete paved track, would be selected for at least parts of the Badminton route where maintenance conditions were a little severe. Obviously this must have been considered and perhaps the Authors would comment on what led them to set aside that solution.

\section{Mr R. J. Coon, British Rail, London Midland Region}

On the West Coast main line of the London Midland Region there is a unique situation. It is not really known what effect the AL6s, with their high unsprung masses, had on the track over the period that they ran regularly at $100 \mathrm{mile} / \mathrm{h}$, and are having now that they are running less frequently at $100 \mathrm{mile} / \mathrm{h}$. Authority has recently been given for conversion of all these locomotives, and it is hoped that the effect of the unsprung masses will be reduced. Unfortunately, the damage has already been done.

102. Having now moved on from the problem of the high unsprung mass of the AL6, we find ourselves dealing with the high lateral forces of the APT. (We have gone from the horizontal to the lateral situation.) I would ask the Authors if they have learnt anything about lateral thrust forces from the $125 \mathrm{mile} / \mathrm{h}$ running, which has now been experienced for a little while. Is alignment being lost as a result of high speed? If so, how are the lines being permanently marked? How are the cants in the track and the alignments being marked? On the curves with a greater cant, is there any tendency to lose the cant and line, in periods of cold weather, for example? We have had experience of this in the Midland Region.

103. Could you describe the maintenance possession patterns? Is it a situation of night maintenance, night tamping? What work can be done during the day?

104. Has there been any reaction from the staff? Has the morale improved as a result of 125 mile/h running? Is it going up with Western Region's image and passenger receipts?

\section{Mr N. S. Ogilvie, British Rail, South Wales}

In South Wales the high speed train is run at normal speeds $-90 \mathrm{mile} / \mathrm{h}$ maximum. There is a heavy freight service, a lot of heavy axle waggons, and a good deal of other freight of normal axle weights. There are track maintenance problems under these conditions.

106. When using the ballast cleaner, we have not always given as murch thought as we might have done to what we are doing outside the width of the cutter bar. People in charge of the ballast cleaning operations will, if one is not careful, still leave a big 
pile of dirty ballast outside the width of the cutter bar. A channel is then formed down the track which has clean ballast in it but which will also retain the water, even on an embankment.

107. It is difficult to get this across to the people who control the job on the Sunday; they will not plan the work of clearing out the ballast shoulder. One needs here to think in terms of mechanization. It is a difficult job. Sometimes a Traxcavator can be used, but many of the sites are difficult and narrow. There are shoulder ballast cleaners, but they tend to tackle too narrow a width. We have to think in terms of $5 \mathrm{ft}$ for the sleeper ends in some cases.

108. Furthermore, it would be helpful if a machine were invented to grade sleepers. If a length of track is breaking up, there are a lot of washy sleepers and one has to use an automatic ballast cleaner. But in South Wales there are many sites with two or three washy sleepers in one place and another two or three maybe a quarter of a mile away, and it is not economical to use a ballast cleaning machine. However, with a lot of these sites on a main line section of $10-15$ miles, it is very time- and labour-consuming to do them all manually. Perhaps there might be a machine which could come in under a squadron tamping occupation and complete 25 in a night.

109. With the heavy freight traffic in South Wales, creep in CWR is a problem. There are a lot of curves on moderately fast lines, and sleepers are racking (i.e., there is a differential creep on the two rails). Also, built-up crossings tend to pull apart or thrust up with the rail creeping. It is not obvious how one can deal with this on a maintenance basis. One could put rail anchors on, but the rail will still creep up to the point where the rail anchors finish. Is the Pandrol fastening adequate to control rail creep in CWR?

110. On the busiest lines in South Wales it is necessary to provide 30 sleepers per $60 \mathrm{ft}$ length where major work is being done, although this has to be done entirely manually and it occupies a great deal of the limited manpower resource on a Sunday.

\section{Mr P. G. Payne, Divisional Civil Engineer. British Railways, Newcastle}

It is not unusual for curves to move 'inwards' with time, heat or mechanical maintenance. I do not think that the circular curve is the biggest problem. What is more difficult is the constant need for design lining and tamping the transition. Have the Authors a procedure for this work? On the north end of the London Midland Region datum pegs were being placed in transition curves.

112. The question $\mathrm{Mr}$ Cope raises on dipped joints and rail grinding is interesting. I have not experienced the effects of rail grinding but expect the grinding train later this year. Have the Authors experience as to what degree of 'dip' can be successfully ground? Does one get the improvement in the body of the rail, which is the worst part from the corrugation point of view, or from the weld grinding also?

113. It was realized before the HST service was introduced that there would be difficulty in obtaining margins. The maintenance margins (for attending to failed welds, unloading ballast and shoulder ballasting) are now extremely critical. New arrangements have to be made with our operating colleagues. On the northern part of the East Coast main line the work will be pushed back into nights-with all the attendant problems. I would be interested to hear the experience of our Western Region colleagues in this respect.

114. Mr Ogilvie makes an interesting reference to the problems of cesses. The Eastern Region is aiming to provide $15 \mathrm{in}$. of ballast beneath CWR. This is an enormous hole when one comes to use ballast cleaners or track shovels with all the problems of filling it in again before opening the service, leading to weekday ballast unloading problems, and accentuating the follow-up work. A procedure used with some success on Newcastle Division in providing cesses of adequate widths and safety, in the winter period, is to put a small machine on the shoulder and doze the shoulder right out and make that into the top of the embankment. Fresh ballast is then unloaded to form a shoulder. That achieves three benefits: it gets rid of the trench/channel after ballasting 
nicely; it gets rid of obstructions, weeds and general debris that has lain about for years; and it achieves a continuous $2.5 \mathrm{~m}$ cess which is required for high speed running. Eastern Region has chosen continuous $2.5 \mathrm{~m}$ cesses to be completed before speeds are raised over $100 \mathrm{mile} / \mathrm{h}$. The northern part of the Division will be completed for the May 1979 timetable. The achievement of continuous cesses has proved to be much easier than was thought initially.

115. To help Mr Ogilvie - I found a small machine with a body $3 \mathrm{ft}$ wide, which could move up and down the cess and complete a lot of work in a working week, between trains, far more than one would with manpower, or by a larger machine fully protected. Our operating colleagues accepted this as not being an obstruction to be protected. This allowed the achievement of the continuous cess within the time allowed-which was very short up to the May 1978 service.

116. Regarding the question of ballast bags behind the ballast cleaner, if one is reballasting for $15 \mathrm{in}$. of ballast there is a great deal of lifting required. The Engineer is being exhorted to open our track at $30-40 \mathrm{mile} / \mathrm{h}$. May I make an urgent plea: rather than modify the cleaners to isolate completely the working area for placing ballast bags, may the ballast cleaner be modified to have a drop chute to lay the ballast bags? This could save considerable time in the lifting required behind ballast cleaning.

\section{Mr A. W. Shilston, Consulting Engineer}

It is to be inferred from the Paper that the refurbishment of the existing London-toBristol Western Region track to sustain high speed trains has been undertaken on the basis of the retention of the existing system and pattern of concrete sleepers. It would be informative and add historical perspective if the Authors could make reference, in relation to the time scale, to the general introduction and utility of concrete sleepers on the London-to-Bristol route and the extent to which these are now standardized throughout the Western and other regions.

118. Is there any recognized basis of track design analogous to that developed for the design of road pavements? For example, is there any particular magic in a ballast depth below the underside of sleeper of $300 \mathrm{~mm}$ which seemed to be the norm?

119. The need for embankment grouting over $2 \frac{1}{4}$ miles of the HST route (Table 2) was a consequence of the examination of the trial holes taken out at $100 \mathrm{yd}$ intervals throughout the route on both up and down lines $(\S 8)$. Was the trial holing and grouting carried out by direct labour? What was the general approach towards fixing the depth of trial holes in embankment structures, and what type of conditions revealed by the examination of the cores led to the introduction of embankment grouting?

120. I have an impression that Western Region have evolved idiosyncratic grouting techniques for stabilizing railway track embankments and these have been the subject of articles in the technical press. It would be helpful if the Authors could provide the reference to the latest Western Region experience in this field.

Mr A. J. Falk, National Institute for Transport and Road Research, CSIR. South Africa

The amount of work involved in a project of this nature must be considerable, as is indicated by the total time span for the modernization works $(1971-76)(\S 40)$. The diversity of some of the major works, from bridge rebuilding to track slewing, must surely have created manpower difficulties within the direct labour organization. Could the Authors please indicate the type of work which was carried out by railway staff and that which had to be done by contract?

122. Commenting on the adverse aerodynamic effects caused by the passage of a train travelling at high speeds, the Authors indicate that deeper refuges were required in tunnels and cuttings $(\S 64)$. Similarly, warning lines and notices have been placed on station platforms for the protection of passengers. What warning period is given 
to track workers by the train-activated and portable warning devices used? Also, are passengers warned verbally of the need to stand clear of platform edges?

123. Further to the question of safety, men working on the track invariably have hand tools and equipment with them. I would be grateful if the Authors would indicate what additional care must be exercised in protecting such equipment from accidents caused by the suction effects of passing trains.

\section{Mr M. Arshad, Kenya Railways}

Western Region has certainly been fortunate in inheriting a large route out of London that required comparatively small civil engineering works to improve track alignment for running trains at $125 \mathrm{mile} / \mathrm{h}$. I have had the opportunity to travel on a part of the route and I must congratulate those concerned for the fast and smooth ride.

125. I note from $\$ 6$ that the high standard of track geometry could only be achieved with CWR. Keeping in mind the other factors, I would be interested to know what the maximum speed would be restricted to if the standard gauge track consisted of $60 \mathrm{ft}$ rails or $300 \mathrm{ft}$ panels.

126. I would like to have seen more technical details on horizontal and vertical curves in the Paper and would therefore enquire on the sharpest horizontal curve on the route with $150 \mathrm{~mm}$ cant permitting design speed of $125 \mathrm{mile} / \mathrm{h}$.

127. Little mention is made of any improvement of gradients and I presume the existing gradients were found within the permissible limits. Would the Authors give the ruling gradient and some information on vertical curves where modifications, if any, were made?

128. Has the higher speed been achieved purely on track geometry or has the new rolling stock, perhaps with a lower centre of gravity, been a contributory factor?

129. What is the present ruling on side wear of rails in curves? Have new limits been laid down in this respect due to speed or frequency of the trains? The force $P_{1}$ for HST is $20 \%$ more than for the Deltic engine and over $16 \%$ more than for $86 / 1$ class locomotives. What effects are expected on the welds in the CWR? This higher force is bound to reduce the life of thermit welds and hence give higher maintenance costs. Perhaps the Western Region has relaid the thermit-welded sections with welds by other methods. I would be interested to learn the method adopted for the purpose of HST.

130. What safety exists if the engine on the front breaks down when a HST is running at over, say, $100 \mathrm{mile} / \mathrm{h}$ ? Will the power in the rear cut off automatically?

\section{Messrs Collins, Black and Tyrer}

The main practical result of the studies of track and vehicle as a single dynamic system mentioned by the President has been the realization that axle loads and unsprung masses of the higher speed trains must be limited if the present track structure is to suffice. Table 1 demonstrates the Mechanical Engineer's success in this respect.

132. It is hard to generalize on permanent way maintenance costs. It is difficult to pick out the costs attributable to passenger trains and those attributable to heavy axle freight trains using the same lines. So far, no increase in cost has been noticeable since the high speed service was introduced, but only time will tell. So far the increase in passenger traffic has exceeded $30 \%$.

133. Messrs Coon and Labrum comment on experience in the London Midland Region of British Rail. Certainly greater efforts are having to be made to maintain a good vertical profile generally, and particularly at welds and insulated joints. Hammering at these points usually initiates ballast attrition and the formation of washy places. While it is too early to say that there has been an acceleration in the rate of deterioration, there has been less success in maintaining and improving the vertical profile than the horizontal. This suggests that the horizontal forces generated by the higher speeds have been adequately resisted by the track structure. Tamping and cold weather tend to pull the heavier canted curves downhill on the high speed route as elsewhere. The methods 
of monumenting and marking cants are described in $\$ 30$ and Fig. 6 of the Paper, but the Authors would not suggest that the $75 \mathrm{~mm}$ square peg provides a truly permanent monument. As a result, a large amount of time-technical staff time and Hallade Gang time, is spent in resurveying transitions prior to design lining. Most of the mechanical maintenance involves design lining on the high speed route. The possession pattern to carry out this work has varied along the route:

Acton-Didcot (4 tracks) - week nights and weekends

Didcot-Wootton Bassett (2 tracks) - weekends only

Wootton Bassett-Westerleigh Jc. (2 tracks)-week nights (squadron only) and weekends.

Thus the only daytime work is at weekends, but nevertheless the average frequency of mechanized maintenance has been twice per year. Selective maintenance based on the regular track recordings has been the general practice. Possessions for other work, such as ballast dropping, are becoming harder to obtain year by year.

134. Logistically, it would have been impossible to fit in the construction of slab track with the other work during the Badminton line blockade. There would have been merit in providing slab track in Chipping Sodbury Tunnel but it is doubtful whether the formation conditions would have suited its use elsewhere.

135. Morale is a little difficult to measure at any given time, but undoubtedly the success of the new high speed service has given a considerable boost to everyone in contact with it on the Western Region.

136. Mr Ogilvie mentions creep in CWR and asks if the Pandrol fastening is adequate to control it. This phenomenon is certainly not peculiar to the high speed route. However, the reduction of toe load with the Pandrol fastening is usually associated with deterioration of the insulators, which can be changed fairly simply.

137. Mr Payne asks about the use of a rail grinding train to improve dipped welds. The train deals very effectively with peaked and hardened flash butt welds and improves the profile at a dip to a depth of say, $1 \mathrm{~mm}$; but where excessive dipping has occurred, straightening and/or building-up and grinding is normally required.

138. Mr Shilston asks about the use of concrete sleepers. These are now standard throughout British Rail and have been laid with all the CWR between London and Bristol from the early 1960 s to date. Their spacing has been reduced over this petiod from 24 per $60 \mathrm{ft}$ length to 28 or 30 per $60 \mathrm{ft}$.

139. Research and experience in many countries has arrived at a minimum requirement of $300 \mathrm{~mm}$ of ballast beneath concrete sleepers for fast or heavily trafficked main lines. Greater depths are specified by some Administrations for new lines.

140. The trial holing mentioned in $\$ 8$ indicated the extent of ballasting and blanketing work needed. Sites for grouting were usually identified by a loss of top and/or cross level in the track, sometimes coupled with a visible movement of the embankment slope. The extent and location of this movement has been checked by sinking alkathene tubing into the slope and measuring its distortion. The grouting techniques used on the Western Region and elsewhere on British Rail are described by Purbrick and Ayres. ${ }^{5}$

141. Mr Falk asks about the use of contractors for carrying out the work described. The vast majority of the track work was carried out by railway staff. Additional gangs were recrujted on the Bristol Division for this purpose. On the London Division, where recruitment is more difficult, some track work is always carried out by contractors working alongside railway staff. The work on the high speed route was no exception. The parallel work of constructing depots for the maintenance of the trains was all carried out by contract.

142. Turning to the safety aspects which Mr Falk mentions, the warning time needed by track workers depends on the nature of the work being carried out. However, generally a minimum of $20-25 \mathrm{~s}$ (i.e., approximately $\frac{3}{4}$ mile sighting distance) is necessary, but this has to be increased with certain activities (e.g., crossing welding). The fixed installation at Alderton Tunnel operated from the track circuits gives an 
average $40 \mathrm{~s}$ advance warning. There has been no difficulty with tools laid at the line side in the usual way.

143. Passengers on station platforms are not warned of the approach of a high speed train but they have heeded the warning notices and the yellow warning lines very well.

144. Answering Mr Arshad's questions, the maximum speed normally permitted over jointed track (normally $60 \mathrm{ft}$ panels) on the Western Region has been $90 \mathrm{mile} / \mathrm{h}$; $300 \mathrm{ft}$ panels are not used.

145. The sharpest curve giving $125 \mathrm{mile} / \mathrm{h}$ running using the criteria set out in Table 3 has a radius of 93 chains (1900 $\mathrm{m}$ approx.). No modifications were needed to vertical curves. The ruling gradients are 1 in 100 at Dauntsey on the route via Bath and 1 in 300 at Chipping Sodbury on the route via Badminton. The higher speeds have been permitted on the basis of track geometry and condition. There is no appreciable difference in the centre of gravity of the HSTs, nor do they tilt.

146. The rules on side wear of rails have not been changed, although the reuse of the reverse face of a side cut rail, after turning or transposing, has been restricted to lower speed lines. Research into riding over rails with 'squared' gauge corners suggests that hunting results at higher speeds (approx. $80 \mathrm{mile} / \mathrm{h}$ and above).

147. There has been no evidence so far to suggest an increased failure rate of thermit welds on the high speed route and they have not been replaced by any other type of weld. However, much greater emphasis is being placed on the maintenance of a good vertical profile at welds, both flash butt and thermit. Programmes of straightening dipped welds, building up cupped welds and grinding off peaked welds are being increased.

148. The HST can still run with one engine out of action. There is still at least $2000 \mathrm{hp}$ available to pull or push the train, albeit at speeds less than $125 \mathrm{mile} / \mathrm{h}$.

\section{Reference}

5. Purbrick M. C. and Ayres D. J. Use of aerated cement grout and mortar in stabilization of slips in embankments, large-scale tunnel repairs, and other works. Proc. Instn Civ. Engrs, Part II, 1956, 5, Feb., 52-84. 